\title{
PERFIL DE SENSIBILIDADE ANTIMICROBIANA IN VITRO DE JUREMA PRETA E NEEM SOBRE AMOSTRAS DE STAPHYLOCOCCUS SP. ISOLADAS DE MASTITE EM BÚFALAS
}

\author{
A.V. Pereira ${ }^{1 *}$, K.M.S. Lôbo ${ }^{1 *}$, D.A.C. Bezerra ${ }^{1}$, O.G. Rodrigues ${ }^{2}$, \\ A.C.R. Athayde ${ }^{2}$, R.A. Mota ${ }^{3}$, E.Q. De Lima ${ }^{2}$, E.S. de Medeiros ${ }^{3 * *}$
}

${ }^{1}$ Universidade Federal de Campina Grande, Av. Universitária, s/no, CEP 58708-110, Patos, PB, Brasil. E-mail: andreiavet@hotmail.com

RESUMO

\begin{abstract}
Os bubalinos apresentam doenças semelhantes às de bovinos, como a mastite, causando grandes prejuízos pecuaristas, no que se refere a terapêutica. $\mathrm{O}$ uso indevido de antibióticos aumenta a resistência, o que torna cada vez mais difícil o tratamento da mastite, devido a necessidade de descobrir novos compostos que sejam eficazes. Este trabalho visa avaliar alternativa de tratamento da mastite com plantas doSemi-árido paraibano Jurema preta [Mimosa tenuiflora (Wild) Poiret] e Neem (Azadiractaindica). As folhas de Neem foram coletadas em árvores de fazendas do Município de Patos, PB, e casca de Jurema preta foi da fazenda da Universidade Federal de Campina Grande, UFCG, Campus de Patos, em seguida, preparado o extrato etanólico. As amostras de Staphylococcus sp. foram coletadas de leite de búfalas com mastite subclínica e semeadas em placas de Petri contendo ágar-base acrescido de $8 \%$ de sangue desfibrinado de ovino. As placas foram incubadas em estufa bacteriológica a $37^{\circ} \mathrm{C}$ e a leitura foi realizada com 24 e 48h. Os ensaios foram realizados em duplicata e o resultado final foi determinado pela média aritmética dos halos de inibição. O extrato etanólico de Jurema preta foi eficaz quando comparado ao de Neem, sobre Staphylococcus coagulase negativa isolados de casos de mastite subclínica em búfalas.
\end{abstract}

PALAVRAS-CHAVE: Bubalinocultura, mastite, tratamento, Staphylococcus sp.

\section{ABSTRACT}

PROFILE OF THE IN-VITROANTIMICROBIAL EFFECTIVENESSOF EXTRACTSOF JUREMA PRETA AND NEEM AGAINST STAPHYLOCOCCUS SP. ISOLATED FROM MASTITE IN BUFFALOES. Buffaloes ranching presents illnesses similar to those of cattle, such as mastitis, causing losses for the producers, in regard to therapeutics. The improper antibiotic use of antibiotics increases the bacteria's resistance, making it increasingly more difficult to treat mastitis, owing to the need to discover new effective compounds. The present study was aimed to evaluate the alternative control of mastitis with plants of the semi-arid region of Paraiba State, Brazil: jurema preta [Mimosa tenuiflora (Wild) Poiret] and neem (Azadiracta indica). The leaves of neem were collected on farms in the county of Patos, and the bark of jurema preta was collected from the farm of the Federal University of Campina Grande UFCG, Campus of Patos, with subsequent preparation of the ethanolic extract. The samples of Staphylococcus sp. were collected from milk of buffaloes with subclinical mastitis and sown in Petri plates containing agar-base complemented by $8 \%$ of defibrinated sheep blood. The plates wereincubated in a bacteriological chamber at $37^{\circ} \mathrm{C}$, and the reading was carried out at 24 and $48 \mathrm{hs}$. The assays were carried out in duplicate, and the final result was determined by the arithmetic mean of halo inhibition. The ethanolic extract of jurema preta was efficient when compared with that of neem, on coagulasenegative Staphylococcus isolated from cases of subclinical mastitis in buffaloes.

KEY WORDS: Buffalo ranching, mastitis, treatment, Staphylococcus sp.

\footnotetext{
${ }^{2}$ Universidade Federal de Campina Grande, Unidade Acadêmica de Ciências Biológicas, Patos, PB, Brasil. ${ }^{3}$ Universidade Federal Rural do Pernambuco, Recife, PE, Brasil.

*Pós-Graduação em Zootecnia pela UFCG, Bolsista do CNPq.

**Pós-Graduação em Medicina Veterinária pela UFRPE.
} 


\section{INTRODUÇÃO}

Os bubalinos apresentam problemas sanitários semelhantes aos bovinos e, dentre os fatores que interferem no desenvolvimento pleno da atividade pecuária, a mastite ocupa lugar de destaque causando prejuízos relacionados a redução na capacidade produtora dos rebanhos infectados (SILva, 1999). Contudo CARVALHO et al. (2007) relataram que o padrão de contagem de células somáticas (CCS) para bubalinos é diferente do normalmente encontrado em bovinos. Os baixos valores de CCS não indicaram necessariamente a ausência de infecção intramamária. Os parâmetros de CCS utilizados para bovinos podem não ser adequados para monitoramento de mastite em rebanhos de bubalinos.

A mastiteé um processo decaráter principalmente infeccioso, onde está envolvida uma série de microorganismos, comumente de origem bacteriana, e possivelmente os fungos e leveduras, as algas e mais raramente, os vírus (LANGONI, 2007). O conhecimento sobre esses micro-organismos e suas interações com a glândula mamária em um determinado ambiente e sistema produtivo são os requerimentos mais importantes no estabelecimento de um sistema de controle efetivo (Мота, 2008).

A higiene é um cuidado imprescindível na exploração leiteira de búfalos, pois estes animais têm predileção por terrenos alagadiços. Por falta de informações sobre a espécie Bubalina, utilizam-se para o controle da mastite as mesmas técnicas de criação e manejo indicadas para os bovinos, além disso, o uso indiscriminado de produtos químicos agridem o meio ambiente e deixam resíduos no leite e carne dos animais, além de favorecer o rápido desenvolvimento de resistência que é traduzida em aumentos de casos clínicos e perdas produtivas (NASCIMENTO; CARVALHO, 1993).

O uso de extratos vegetais e fitoquímicos com fins medicinais é uma das mais antigas formas de prática medicinal da humanidade. Devido à atividade metabólica secundária aumenta a busca pelos vegetais superiores que são capazes de produzir substâncias antibióticas, utilizadas como mecanismo de defesa contra predação por micro-organismos, insetos e herbívoros (Gotlieb, 1981). As propriedades terapêuticas dos princípios e medicamentos fitoterápicos começam a ganhar cada vez mais espaço no tratamento veterinário, profissionais adeptos da fitoterapia revelam alta freqüência de sucessos em tratamento de parasitoses e enfermidades infecciosas, inclusive em tratamentos de mastites (CosTA, 1998).

O uso de extratos vegetais de conhecida atividade antimicrobiana podem adquirir significado nos tratamentos terapêuticos. Várias espécies vegetais têm sido usadas, por tais características, através de com- postos sintetizados pelo metabolismo secundário de plantas (LOGUERCiO et al., 2005). Estudos relatam que a atividade antimicrobiana está relacionada à presença de alcaloides, fenóis, polifenóis, saponinas, triterpenos e esteroides encontrados no extrato vegetal e frações (KuETE et al., 2006).

O Neem (Azadiracta indica), originário do Sudeste da Ásia, região de clima tropical, pertence à família Meliaceae, sendo cultivado em todos os países da África, na Austrália e América Latina. Foi introduzido no Brasil em 1993, possui diversas aplicações, em especial como antisséptico, curativo e vermífugo. Entre a sua ampla utilização, possui particularidade de atuar como acaricida, fungicida enematicida (BENOITVical et al., 2003). Além dessas propriedades, o óleo extraído do fruto do Neem apresenta atividade antibacteriana, incluindo Staphylococcus aureus (MANСЕВо et al., 2002). Estudiosos preferem dar a essas substâncias inibidoras, de origem vegetal, a denominação de fintocidas ou de substâncias semelhantes a antibióticos "Antibiotic Like-Substances" (GEISSMAN, 1963).

A Jurema preta [Mimosa tenuiflora (Wild) Poiret] é uma leguminosa da subfamíliaMimosoidae, éarvoreta, com cerca de 5-7 m de altura, com casca de cor castanha muito escura, às vezes acinzentada, grosseira, rugosa, fendida longitudinalmente e tem entrecasca vermelho-escura. É utilizada na medicina caseira, em tratamentos de queimaduras, acne e problemas de pele (MAIA, 2004). Em estudos etnofarmacológicos foi possível observar que a Jurema apresenta propriedades antimicrobianas e que, ao mesmo tempo, pode preencher critérios de preservação ambiental e manejo autossustentável semelhante a outras plantas nativas tais como: Anacardium occidentale (cajueiro), Pterodon emarginatus (sucupira), Copaiferalangsdorffii (copaíba); e Anadenanthera colubrina (angico) (Rodrigues, 1996).

A abundância de taninos eflavonóis detectada no extrato da casca da $M$. tenuiflora é a provável responsável pela atividade antimicrobiana verificada em Staphylococcus epidermitis, Escherichia coli, Pseudomonas aeruginosa, Micrococcus luteus e Acinetobacter calcoaceticus, além de fungos como Microsporum gypseum, M. canis, Thrichophyton mentagrophytes, T. rubus e Chaetomium indicum (Lozoya et al., 1989). Os principais grupos de compostos com propriedades antimicrobianas, extraídos de plantas incluem: terpenoideseóleos essenciais (Torssel, 1989); flavonas, flavonóis e flavonoides (FESSENDEN, 1982), tanino (ScAlbert, 1991) e cumarinas (O'Kennedy; Thornes, 1997).

De acordo com CHANDER; BAXI (1975), as bactérias dos gêneros Staphylococcus e Streptococcus são as principais causas infecciosas de mastite bubalina. A bubalinocultura vem enfrentado alguns problemas 
com a mastite e antes que o uso indiscriminado dos produtos químicos crie resistência às bactérias, devese buscar novas alternativas de tratamento. Este trabalho objetiva avaliar a atividade antimicrobiana de extrato etanólico de Jurema preta (M. tenuiflora)nativa de nossa região e Neem ( $A$. indica) exótica em nosso país, sobre Staphylococcus coagulase negativa isolados de casos de mastite subclínica de búfalas.

\section{MATERIAL E MÉTODOS}

\section{Local de execução da pesquisa}

O presente trabalho foi desenvolvido nos laboratórios de Ciências Químicas e Biológicas da Universidade Federal de Campina Grande-UFCG do Centro de Saúde e Tecnologia Rural - CSTR, e Laboratório de doenças infecto contagiosas da UniversidadeFederal Rural de Pernambuco - UFRPE, Recife.

\section{Coleta de folhas de Neem e de Jurema preta}

As folhas de Neem foram adquiridas em fazendas comerciais do Município de São José de Espinharas, PB. Após a coleta foram postas para secagem em estufa de ventilação forçada $\mathrm{a} \pm 60^{\circ} \mathrm{C}$ por um período de 24 h e em seguida maceradas e acondicionadas em reservatórios de vidro até seu uso.

A casca da Jurema preta foi adquirida no Centro de Saúde e Tecnologia Rural - CSTR, Campus de Patos UFCG, PB. Foi colocada para secagem ao ar por 48h, em seguida secada na estufa de ventilação forçada a $60^{\circ}$ C por 24h. Logoapós o material foi pesadoe moído.

A exsicata e a identificação botânica foram realizadas pelo herbário Dárdano de Andrade Lima na Universidade Regional do Cariri-URCA, Crato, CE, pela botânica curadora do herbário a professora $\mathrm{Dr}^{\mathrm{a}}$ Maria Arlene Pessoa da Silva. A exsicata da Jurema Preta foi depositada no herbário sob o número 3275 e a do Neem sobre número 3276.

\section{Obtenção dos extratos etanólicos}

Foram utilizados $100 \mathrm{~g}$ de folha de Neem para $1 \mathrm{~L}$ de etanol e $500 \mathrm{~g}$ de casca do caule de Jurema preta para $1 \mathrm{~L}$ de etanol. A preparação das plantas para a obtenção do extrato foi realizada a partir do peso inicial da matéria seca e logo em seguida adicionado álcool etílico para análise (P.A.), deixando a mistura sob extração por $72 \mathrm{~h}$, a determinação e concentração foi realizada segundo a metodologia deMATOs(1997). O extrato foi diluído com água destilada em: 1:1; 1:2; $1: 4 ; 1: 8 ; 1: 16 ; 1: 32 ; 1: 64 ; 1: 128 ; 1: 256$ e 1:512, para a determinação da atividade antimicrobiana das plantas testadas.

\section{Aquisição das amostras dos animais infectados}

Secreções lácteas foram coletadas de 140 búfalas leiteiras, perfazendo um total de 554 amostras, no período de janeiro a fevereiro de 2007. A coleta das amostras foi realizada após lavagem da teta comágua e sabão, secagem com papel toalha e desinfecção do óstio do teto, utilizando-se álcool etílico a $70^{\circ} \mathrm{GL}$. Coletou-se aproximadamente $5 \mathrm{~mL}$ deleite por quarto mamário, de maneira asséptica, com tubo inclinado na posição horizontal (BоUсHот et al., 1985). Estas amostras foram armazenadas em tubos rosqueados estéreis, identificados e enviados sob refrigeração em caixas de material isotérmico, para a realização do exame microbiológico no Laboratório de Doenças Infecto-contagiosas da Universidade Federal de Pernambuco.

\section{Exame microbiológico do leite}

As amostras foram previamente homogeneizadas e, posteriormente, alíquotas de 0,1 mLforam semeadas em placas de Petri contendo ágar-base acrescido de $5 \%$ de sangue de ovino desfibrinado. As placas foram incubadas em estufa bacteriológica a $37^{\circ} \mathrm{C}$ e a leitura foi realizada 24 e 48 horas após. Para a identificação da bactéria, foram observadas as características macromorfológicas das colônias e microscópicas à técnica do Gram segundo QuinN et al. (1994). Após identificação, os isolados foram repicados para o caldo cérebro coração (BHI) e incubados em estufa bacteriológica a $37^{\circ} \mathrm{C}$, até a turvação do meio.

\section{Identificação das cepas de Staphylococcus sp.}

Para a identificação de $S$. aureus todas as cepas de estafilococos foram submetidas aos testes de produção de coagulase livre (Plasma Coagulase EDTA, Coagu-Plasma LB - Laborclin, Brasil), DNAse (Agar DNAse - DFICO) e catalase (SILvA et al., 1997). As provas de produção de acetoína, fermentação da glicose (aerobiose) e do manitol (aerobiose e anaerobiose) foram realizadas segundo MAC FADDIN (1980) e os isolados classificados de acordo com BAIRD-PARKER (1990).

\section{Estudo da atividade antimicrobiana in vitro de Neem e Jurema preta}

As linhagens foram cultivadas em caldo nutritivo (BHI- Brain Heart Infusion - DIFCO); incubadas a $37^{\circ}$ C por 18-24h.

A concentração inibitória mínima (CIM) dos extratos etanólicos de $A$. indica e $M$. tenuiflora sobre as linhagens bacterianas foi determinada pela atividadeantimicrobiana, com base no diâmetro dos halos de 
inibição, sendo estes superiores a $12 \mathrm{~mm}$. As placas foram incubadas em estufa bacteriológica a $37^{\circ} \mathrm{C}$ por um período de $24 \mathrm{~h}$ (Silva, 2003). Foram utilizados poços de aproximadamente $6 \mathrm{~mm}$ de diâmetro, os quais receberam $50 \mu \mathrm{L}$ da solução do extrato diluído em água destilada, de acordo com as diluições préestabelecidas.

Os ensaios foram realizados em duplicata, acompanhados de controle positivo com o antibiótico ampicilina e controle negativo com metanol. A sensibilidade da amostra foi considerada para medidas superiores a $12 \mathrm{~mm}$ (SILVA, 2003). Os resultados foram submetidos à análise estatística descritiva.

\section{RESULTADOS E DISCUSSÃO}

O extrato do Neem mostrou-se eficaz na concentração de 1:1, resultado que se assemelha com os estudos de MANCEBoetal.(2002), quando demonstram a atividade biológica do Neem no controle de larvas de Cedrela odorata (Fig. 1). O extrato da Jurema preta apresentou atividade biológica efetiva onde, nas diluições 1:1; 1:2; 1:4; 1:8; 1:16; 1:32; 1:64 e 1:128 com a média do halo de inibição foi de $25 \mathrm{~mm}$ (Fig. 2). Os achados encontrados no presente trabalho corroboram com os de Alves etal. (2000) ao avaliarem o extrato da $M$. tenuiflora sobre $S$. aureus e da E. coli. MeCKESLozoyA et al. (1990) ressaltaram que o tanino, composto químico abundante na Jurema, é o provável responsável por essa atividade antimicrobiana.

Nas amostras testadas com o extrato de Jurema registrou-se $100 \%$ de eficácia antimicrobiana, pois apresentaram halos de inibição superior a $12 \mathrm{~mm}$ nas concentrações de 1:1 a 1:3 (Fig. 3). VANKA et al. (2001) verificaram o efeito do extrato de Neem sobre os níveis salivares de Streptococcusmutans eLactobacillus por um período maior do que dois meses. Os resultados obtidos neste estudo com o extrato de neem corroboram com os realizados por RAVAGNANI (2006), constatando

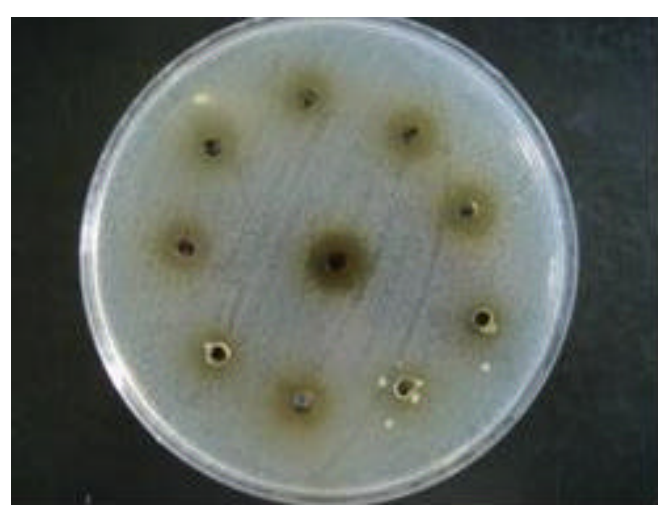

Fig. 1 - Atividade antimicrobiana do extrato de Azadiracta indica sobre Staphylococcus aureus, período de 48 horas de incubação. que o extrato testado não apresentou atividade antimicrobiana sobre cepas de $S$. mutans nas concentrações $3.200 \mu \mathrm{g} / \mathrm{mL}, 1.600 \mu \mathrm{g} / \mathrm{mL}, 800 \mu \mathrm{g} / \mathrm{mL}, 400$ $\mu \mathrm{g} / \mathrm{mL}, 200 \mu \mathrm{g} / \mathrm{mL}$ e $100 \mu \mathrm{g} / \mathrm{mL}$ não sendo possível verificar a CIM.

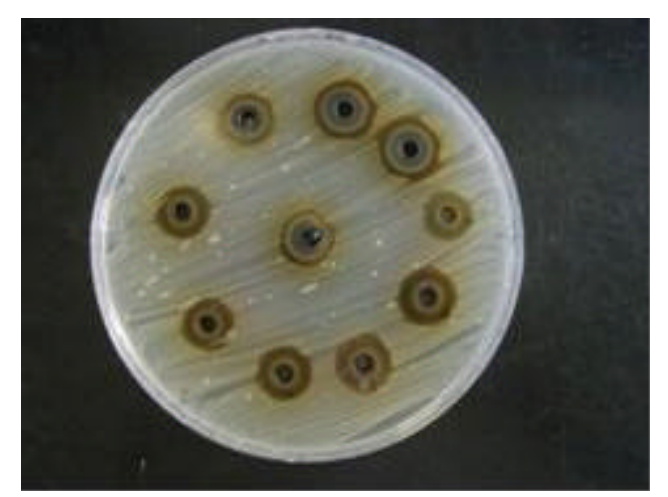

Fig. 2 - Atividade antimicrobiana do extrato de Mimosa tenuiflora sobre Staphylococcus aureus, período de 48 horas de incubação.

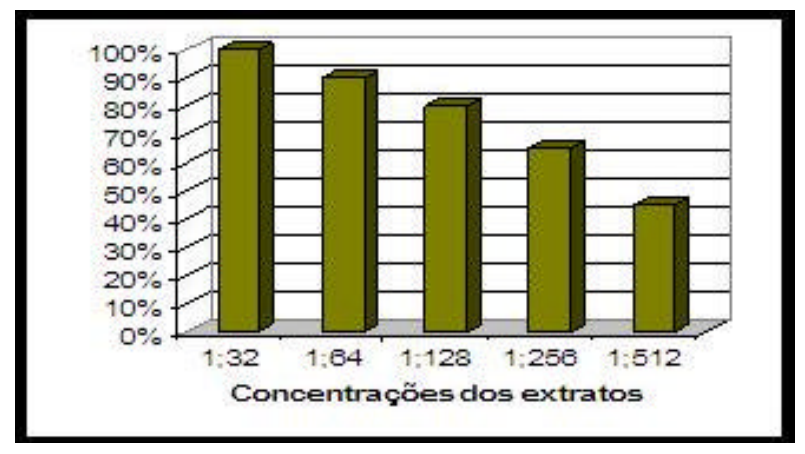

Fig. 3 -Percentual de inibição do extrato bruto de Mimosa tenuiflora (wild) Poiret sobre amostras representativas de Staphylococcus aureus coagulase negativa (in vitro).

Estudos relatam a alta atividade antimicrobiana obtida com o extrato de $M$. tenuiflora sobre cepas de Streptococcus sp. e Staphylococcus sp. (HeINRIch et al., 1992). A diluição é inversamente proporcional a eficácia do extrato, ou seja, a medida que a diluição aumentava observava-se uma redução na atividade biológica: 1:64 (90\%); 1:128 (80\%); 1:256 (65\%); 1:512 (45\%). Segundo BEZERRA (2008), o extrato etanólico do cerne de Jurema preta apresentou melhor atividade bacteriostática contra os micro-organismos testados nas concentrações de $10 \%$ a 1,25\% com maior efeito sobre $E$. coli, no entanto, a $P$. aeruginosa, $S$. aureus e $A$. caviae apresentaram sensibilidade ao extrato apenas nas concentrações $10 \%$ e $5 \%$. De SouzA et al. (2002) observaram efeito antimicrobiano em extratos dessa planta frente a bactérias Gram positivas e Gram negativas, inibindo também S. aureus. MECKEs-LozoyA et al. (1990) avaliaram o potencial antimicrobiano do pó da casca de Jurema preta a partir de extratos acetato de 
etila, n-butanólico e metanólico sobre os microorganismos S. aureus e E. coli. e ambos foram sensíveis aos extratos, com destaque para o extrato acetato de etila, que apresentou os maiores halos de inibição. GONÇALVES et al. (2005) avaliaram a atividade do extrato hidroalcoólico de jurema preta sobre $S$. aureus e $P$. aeruginosa onde obtiveram resultados que confirmam a sensibilidade destes micro-organismos ao extrato da planta.

\section{CONCLUSÃO}

O estudo da atividade antimicrobiana de extrato etanólico de Jurema preta (M. tenuiflora (Wild) Poiret) demonstrou maior eficácia comparado ao de Neem (A. indica), sobre Staphylococcus coagulase negativa isolados de casos de mastite subclínica em búfalas. São necessários mais estudos empregando extratos naturais sobre micro-organismos isolados de animais portadores de mastite, visto que pode representar uma forma alternativa na sua terapêutica. $O$ baixo custo para obtenção do extrato alcoólico das plantas utilizadas serve de estímulo para a adoção da prática fitoterápica.

\section{REFERÊNCIAS}

ALVES, T.M.A.; SILVA, A.F.; BRANDÃO, M.; GRANDI, T.S.M.; SMÂNIA, E.F.; SMÂNIA JUNIOR, A.; ZANI,C.L. Biological screening of brasilian medicinal plants. Memórias do Instituto Oswaldo Cruz, v.95, n.3, p.367-373, 2000.

BAIRD-PARKER, A.C. The Staphylococci: an introduction. Journal of Applied Bacteriololy, v.19, p. 1585, 1990.

BENOIT-VICAL, F.O. IMBERT, C.; JEAN-PAUL BON. Antiplasmodial and antifungal activities of iridal, a plant triterpenoid. Phytochemistry, v. 62. p. 747-751, 2003.

BEZERRA D.A.C. Estudo fitoquímico, bromatológico e microbiológico de Mimosa tenuiflora (Wild) Poiret e Piptadenia stipulacea (Benth) Ducke. 2008. 63f Dissertação (Mestrado em Zootecnia) - Universidade Federal de Campina Grande, Patos, 2008.

BOUCHOT, M. C. et al. Diagnostic bactériologique des infections mammaries des bovins. Recueil de Médicine Vetetináre, v.161, p.567-577, 1985.

CARVALHO, L.B.; AMARAL, F.R.; BRITO, M.A.V.P.; LANGE, C.C; BRITO, J.R.F.; LEITE, R.C. Contagem de células somáticas e isolamento de agentes causadores de mastite em búfalas (Bubalus bubalis) Arquivo Brasileiro de Medicina Veterináia e Zootecnia, v.59, n.1, p.242-245, 2007.
CHANDER, S.; BAXI, K.K. A note on diagnosis and treatment of subclinical mastitis in buffaloes. Indian Veterinary Journal, v.52, n.11, p.847-849, 1975.

COSTA, B. Homeopatia na cura e prevenção de doenças. Balde Branco, v.34, julho, p.28-33, 1998.

FESSENDEN, R.J. Organic chemistry. Boston: Willard Grant Pres, 1982.

GEISSMAN, T.A. Flavonoid compounds, tannins, lignins, and related compounds. New York: Elsevier, 1963. 265p.

GONÇALVES, A.L; ALVES FILHO, A.; MENEZES, H. Estudo comparativo da atividade antimicrobiana de extratos de algumas árvores nativas. Arquivos do Instituto Biológico, São Paulo, v.72, n.3, p.353-358, 2005.

GOTLIEB, O. New and underutilized plants in the Americas: solution to problems of inventory through systematics. Interciência, v.6, n.1, p.22-29, 1981.

HEINRICH, M.M.; KUHNT, M.; WRIGT, C.W.; RIMPLER, H.; PHILLIPSON, J.D.; SCHANDELMAIER, A.; WARHURST, D.C. Parasitological and microbiological evaluation of mixe indian medical plants. Journal of Ethnopharmacology, v.36, p.81-85, 1992.

KUETE, V.; TANGMOUO, J.G.; BENG, V.P.; NGOUNOU, F.N.; LONTSI, D. Atimicrobial activity of the methanolic extract from the stem barrk of tridesmostemon omphalocarpoides (Sapotaceae). Journal of Ethnopharmacology, v.104, p.5-11, 2006

LANGONI, H. Mastite bovina conceitos e fundamentos. In: ENCONTRO DE PESQUISADORES EM MASTITES, 4., 2007, Botucatu, SP. Resumos. Botucatu: FMVZ - UNESP, 2007.

LOGUERCIO, A.P.; BATTISTIN, A.; CASTAGNA DE VARGAS, A.; NIURA, A.H.; WITT, M. Atividade antibacteriana de extrato hidro-alcoólico de folhas de jambolão (Syzygium cumini (L.) Skells). Ciência Rural, v.35, n.2, p.371-376, 2005.

LOZOYA, X.; NAVARRO, V.; ARNASON, J.T.; KOURANY, E. Experimental evaluation of Mimosa tenuiflora (Wild.) Poir. (Tepeschohuite) I. Screening of the antimocrobial properties of bark extracts. Archivos de Investigación Medica, v.20, n.1, p.87-93, 1989.

MAC FADDIN, J.F. Biochemical test for identification of medical bacteria. 2nd ed. Baltimore: Williams \& Wilkins, 1980. 527p.

MANCEBO, F.; HILJE L.; MORA, G.A.; SALAZAR, R. Biological activity of two Neem (Azadirachta indica A. Juss., Meliaceae) products on Hypsipyla grandella (Lepidoptera: Pyralidae) larvae. Crop Protection, v.21, p.107-112, 2002. 
MATOS, F.J.A. Introdução à fitoquímica experimental. 2ed. Fortaleza: EUFC, 1997. 141p.

MAIA, G.N. Caatinga - árvores e arbustos e suas utilidades. São Paulo: D\&Z, 2004. p.237-246.

MECKES_LOZOYA, M.; LOZOYA, X.; MARLES, R.J.; SOUCY-BREAU, C.; SEN, A.; ARNASON, J.T. N, NDimenthyltryptamine Alkaloid in Mimosa tenuiflora Bark (Tepescohuite). Archivos de Investigación Medica, v. 21, n.2, p. 175-177, 1990.

MOTA R.A. Aspectos epidemiológicos, diagnóstico e controle das mastites em caprinos e ovinos. Tecnologia. \& Ciência Agropecuária, v.2, n.3, p.57-61, 2008.

NASCIMENTO, C.N.B.; CARVALHO, L.O.M. Criação de búfalos: alimentação, manejo, melhoramento e instalações. Brasília: EMBRAPA - SPI, 1993. 403p.

O'KENNEDY, R.; THORNES, R.D. Coumarins: biology, applications and mode of action. New York: John Willey, 1997.

QUINN, P.J.; CARTER, M.E.; MARKEY, B.K.; CARTER, G.R. Clinical veterinary microbiology. London: Wolf, 1994. 648 .

RAVAGNANI V.A. Avaliação in vitro da atividade antimicrobiana da planta Azadirachta indica (Neem) sobre Streptococcus mutans. 2006. 33f Dissertação (Mestrado em Odontologia) - Universidade do Sagrado Coração, Bauru, 2006.

RODRIGUES, R.R. (Coord.). Trilhas do parque da ESALQ: árvores medicinais. 1996. Piracicaba: ESALQ, 1996. 28p.
SCALBERT, A. Antimicrobial properties of tannins. Phytochemistry, v.30, p.3875-3883, 1991.

SILVA, N. Diagnóstico de mastite em animais de importância economica. In: ENCONTRO DE PESQUISADORES EM MASTITES, 3., 1999. Botucatu, SP. Anais . Botucatu, p.51-55.1999.

SILVA, M.A.R. Influência do extrato da romã (Punica granatum Linn.) sobre plasmídeos nos processos de cura e transmissibilidade genética de Staphylococcus aureus de origem bovina. In: CONGRESSO BRASILEIRO DE GENÉTICA, 49., 2003, Gramado. Anais. Gramado: 2003.

SILVA, N.; JUNQUEIRA, V.C.A.; SILVEIRA, N.F.A. Manual de métodos de análise microbiológica de alimentos. São Paulo: Varela, 1997. 295p.

SOUZA, R.S.O. de Jurema-preta (Mimosa tenuiflora [Willd] Poiret): enteógeno, remédio ou placebo? uma abordagem à luz da etnofarmacologia. 2002. Monografia (Graduação em Ciências Biológicas) - Universidade Federal de Pernambuco, Recife, 2002.

TORSSEL, B.G. Natural product chemistry. A mechanistic and biosynthetic approach to secondary metabolism. New York: John Willey, 1989. 401p.

VANKA, A.; TANDON, S.; RAO, S.R. The effect of indigenous Neem Azadirachta indica mouth wash on Streptococcus mutans and lactobacilli growth. Indian Society of Dental Research, v.3, n.12, p.133-144, 2001.

Recebido em 5/3/08

Aceito em 7/5/09 